University of Wollongong

Research Online

Faculty of Business - Papers (Archive)

Faculty of Business and Law

$1-1-2016$

Is Environmental Protection Beneficial for the Environment?

Alberto Ansuategi

University of The Basque Country

Simone Marsiglio

University of Wollongong, simonem@uow.edu.au

Follow this and additional works at: https://ro.uow.edu.au/buspapers

Part of the Business Commons

Research Online is the open access institutional repository for the University of Wollongong. For further information contact the UOW Library: research-pubs@uow.edu.au 


\title{
Is Environmental Protection Beneficial for the Environment?
}

\begin{abstract}
We analyze a simple endogenous growth model with environmental interactions. Economic production generates emissions of pollutants whose environmental impact is mitigated by abatement activities financed by government expenditure; environmental quality affects preferences but does not play any productive role. We show that government intervention, by reallocating resources from capital accumulation to environmental preservation activities, allows the economy to achieve a sustainable balanced growth path. Along such a path, softer environmental policy regimes lead to win-win outcomes, fostering economic growth and improving environmental quality. Such a result needs to be interpreted as a long run outcome, but it clearly shows that the compatibility between economic growth and environmental improvement is far from automatic. Indeed, in the long run it could paradoxically be the case that both the economy and the environment benefit from low levels of environmental protection.

\section{Disciplines}

Business

\section{Publication Details}

Ansuategi, A. \& Marsiglio, S. (2017). Is Environmental Protection Beneficial for the Environment?. Review of Development Economics, 21 (3), 786-802.
\end{abstract}




\title{
Is Environmental Protection Beneficial for the Environment?*
}

\author{
Alberto Ansuategi ${ }^{\dagger} \quad$ Simone Marsiglio ${ }^{\ddagger}$ \\ Forthcoming in Review of Development Economics
}

\begin{abstract}
We analyze a simple endogenous growth model with environmental interactions. Economic production generates emissions of pollutants whose environmental impact is mitigated by abatement activities financed by government expenditure; environmental quality affects preferences but does not play any productive role. We show that government intervention, by reallocating resources from capital accumulation to environmental preservation activities, allows the economy to achieve a sustainable balanced growth path. Along such a path, softer environmental policy regimes lead to win-win outcomes, fostering economic growth and improving environmental quality. Such a result needs to be interpreted as a long run outcome, but it clearly shows that the compatibility between economic growth and environmental improvement is far from automatic. Indeed, in the long run it could paradoxically be the case that both the economy and the environment benefit from low levels of environmental protection.
\end{abstract}

Keywords: Economic Growth, Environmental Quality, Win-Win Outcomes

JEL Classification: O40, Q50

\section{Introduction}

In the last two decades there has been a growing interest in understanding the links between the effort devoted to reduce the undesirable side-effects of human activities on environmental quality and the economic performance of nations, industries and firms. Since the early 1990s much attention has been placed on the "win-win" opportunity advanced by Porter and van der Linde (1995), stating that stricter environmental regulation would result in environmental benefits and increased competitiveness. The so-called "Porter hypothesis" has given rise to important theoretical controversies and has spurred an extensive empirical literature on the effects of environmental regulation on innovation producing inconclusive (and contested) result:1. However, despite the richness of the academic debate, the translation of this debate into the policy arena has been disappointingly simplistic. Thus, the recent United Nations Conference on Sustainable Development, called Rio+20 (UNEP, 2012) and, more recently, the 2030 Agenda for Sustainable Development (UN, 2015), have arrived in a moment in which political and economic leaders embrace unanimously and

\footnotetext{
${ }^{*}$ We are grateful to Ilaski Barañano and Fabio Privileggi for insightful discussions and comments. We also wish to thank the participants to the seminar held at JCU and the ANZSEE 2012 conference (Gold Coast, QLD, Australia) for their helpful advises and suggestions. All remaining errors are our sole responsibility. Alberto Ansuategi gratefully acknowledges financial support from Spanish Ministry of Science and Innovation (grant ECO2011-25064) and the Basque Ministry of Education, Universities and Research (grant GIC07/56-IT-383-07).

${ }^{\dagger}$ University of the Basque Country, Department of Foundations of Economic Analysis I and Institute of Public Economics, avenida Lehendakari Aguirre 83, 48015 Bilbao, Spain. Email: alberto.ansuategi@ehu.es

${ }^{\ddagger}$ University of Wollongong, School of Accounting, Economics and Finance, Northfields Avenue, Wollongong 2522 NSW, Australia. Email: simonem@uow.edu.au.

${ }^{1}$ Jaffe et al. (2003) and Pasurka (2008) review both theoretical perspectives and empirical studies of the relationship between pollution abatement and competitiveness.
} 
with breathtaking enthusiasm green growth strategies aiming at fostering economic growth and development, while ensuring that natural assets are used sustainably and continue to provide the resources and environmental services which our wellbeing relies upon (OECD, 2015).

The green growth discourse among policymakers is still in a preliminary phase, but eventually its success can have two different types of interpretations. The optimistic interpretation would consider it as a signal that a new consensus is emerging on the fact that economic growth and environmental quality are in many respects complementary. The pessimistic interpretation would underline that in Public Administration rhetoric devoting more resources to environmental protection is wrongly interpreted as a sufficient condition to ensure higher living standards and a healthier environment. The search for "silver bullets" to address environmental and economic challenges at the same time has also been present in the policy prescriptions designed to face the current global economic (and environmental) crisis. Thus, many governments announced stimulus measures in response to the financial crisis of 2007-08, and sizable portions of these stimulus packages were directed at environmental goals (IILS, 2011). These green stimulus measures have also been interpreted as "win-win" policies: meant to stabilize the economy and improve environmental quality.

It is beyond the scope of this paper to discuss the validity of the "win-win" nature of such policies. Instead, we want to illustrate in a very simple theoretical framework that the compatibility between economic growth and environmental improvement is far from automatic and that in the long term it could paradoxically be the case that both the economy and the environment benefit from a lower level of environmental protection. But, again, we do not want our reasoning to be misinterpreted. This theoretical result does not lend support to the argument that (too much) environmental protection does hurt both the economy and the environment. We just want to point out that some forms of environmental protection could lead us in the long term to lower levels of consumption and environmental quality and, therefore, lower levels of welfare. It should be noted that environmental protection comprises a wide array of different measures, some more "reactive" (i.e. treatment of wastewater and effluents) and others more "proactive" (i.e., R\&D aiming at reducing energy/emission intensity of production/consumption activities). If the main responsibility of an Environmental Protection Agency (EPA) is to abate pollution in order to compensate for a reduction in Nature's capacity to provide ecosystem services (and this is the role it will play in our illustrative and simplified model), it may well be the case that those economies with higher levels of environmental protection expenditure will experiment lower rates of economic growth and lower levels of environmental quality in the long run. This is due to the fact that in these economies the EPA will be basically substituting ecosystem services provided by Nature with environmental goods and services that will require the use of resources that cannot be directed to other productive activities.

In order to show our point in the clearest possible way, we focus on the simplest endogenous growth model used in literature to investigate the relationship between environmental policy and economic growth, that is a one-sector model with abatement activities financed by a central authority. In the last decade several progresses in the analysis of the mutual implications between growth and environment have been made (see Xepapadeas, 2003, for a survey). Here we briefly discuss a strand of such a literature, the subset employing one-sector endogenous growth models, which is most closely related to our approach, focusing in particular on the relationship between environmental policy and economic growth (see Smulders, 1999, for a concise survey). The common result in this theory is that economic growth and environmental preservation are to a large extent compatible, since a sustainable balanced growth path along which consumption increases and environmental quality improves generally exists. More controversial is the question related to the relationship between environmental policy and growth, since the net effect of environmental regulation on economic performance depends on the relative magnitude of two opposite effects (Smulders, 1999). On the one hand, environmental preservation activities require to divert some resources from growth enhancing activities (crowding out effect), while on the other hand, environmental improvements may increase productivity (productivity effect). Growth and environment will go hand-in-hand only if the productivity effect is large enough to more than compensate the crowding out effect. 
One of the first works showing that such a result does not have to be taken for granted is Gradus and Smulders' (1993). They consider a Ramsey problem where human activities generate an externality on the environment, which negatively affects households' preferences. Their paper considers alternative models (neoclassical, endogenous growth with one or two sectors) in order to understand how environmental care and long run growth are related in different setups. In their one-sector endogenous growth model, they focus on pollution as a flow variable, emission abatement activities use an exogenous share of output, and unabated pollution increases with the capital stock and falls with abatement effort. Pollution does not have any economic role, it is a mere negative environmental externality. In such a context there clearly exists a tradeoff between economic growth and environmental quality, since there is no productivity effect. This is due to the fact that increasing investment in abatement activities, financed by current expenditure, is needed to improve environmental quality; however, investing in abatement activities also reduces resources allocated to productive investments and thus lowers the economic growth rate. This implies that environmental policy and growth enhancing policy are incompatible, and policymakers cannot achieve at the same time both goals of fast economic growth and healthier environment: win-win outcomes do not exist. The same conclusions hold also in Withagen (1995), which extends the Gradus and Smulders' (1993) work to highlight the importance of considering pollution as a stock variable. Other studies reach more optimistic conclusions by attributing pollution (or alternatively, environmental quality) a positive role in the production of the consumption good (Smulders, 1995; Smulders and Gradus, 1996; Rosendahl, 1997). This introduces a productivity effect which can balance and more than offset the crowding out effect, ensuring that more stringent environmental policies may also foster long run growth 2 . Our paper reaches a similar conclusion on the existence of win-win outcomes, but differently from this last group of studies it does not require the environment to generate any productive effect.

Apart from the already mentioned literature on the Porter hypothesis, the eventual existence of a positive relation between economic growth and environmental quality has often been discussed in the environmental economics literature in relation to the environmental Kuznets curve and double dividend hypotheses. The environmental Kuznets curve hypothesis suggests that, even if in an initial phase of economic development increases in per capita income are associated with decreases in environmental quality, after a certain critical level of per capita income further economic growth can be achieved along with improvements in environmental quality, such that the income and environmental quality relationship is overall U-shaped (Grossman and Krueger, 1995). The positive association between per capita income and environmental quality in this later phase of economic development can be due to the role of economic policy, due for example to increasing returns in abatement activities, but also to other factors independent from public policy, as those related to the luxury good status of environmental quality and the structural changes associated with economic growth (see Brock and Taylor, 2005, for a neat review of theories on the environmental Kuznets curve). The double dividend hypothesis suggests instead that environmental policy, in the specific form of environmental taxes, can lead to both an improvement in environmental quality and an increase in economic efficiency and eventually in per capita income, representing thus an environmental and an economic dividend, respectively (Pearce, 1991). Such a positive relation between environmental and economic outcomes is possible only whenever the environmental tax moves the overall economy's tax structure closer to its optimum, that is the tax structure allowing to minimize distortionary costs (see Markandya, 2005 for a concise review). Our paper however focuses more specifically on the long run impact of environmental protection activities on both economic growth and environmental quality, thus, even it the issues are connected, it does not directly relate to either the environmental Kuznets curve or double dividend literatures.

\footnotetext{
${ }^{2}$ Similar conclusions can be obtained by considering more complex frameworks. Some examples include allowing pollution abatement activities to rely on two different types of capital or to exhibit increasing returns (Michel and Rotillon, 1995; Huang and Cai, 1994; Xepapadeas, 1997; Shieh et al., 2001), enabling the pollution decay function to be decreasing (Chevé, 2000) or extending the analysis to multi-sector models (Bovenberg and Smulders, 1995; Hettich, 1998). See Ricci (2007) for a recent survey of the implications of environmental policy on economic growth.
} 
The paper proceeds as follows. After this brief introduction, section 2 presents our stylized benchmark model, which is a simple growth model that will allow us to illustrate the arguments introduced above. In particular, we consider a one-sector endogenous growth model, where the environment does not play any productive role, and abatement activities are as in Gradus and Smulders (1993). Section 3 provides an alternative model specification, in order to overcome the shortcomings of Gradus and Smulders' (1993) abatement technology; specifically, we follow Bartz and Kelly (2008) to allow abatement to reduce a certain share of pollution. Both the models lead to the same qualitative results, showing that win-win outcomes exist, but differently from what shown in the existing literature, a softer (rather than stricter) environmental policy leads to a faster growth and healthier environment. Section 4 provides a line of interpretation of our results focused on which activities are effectively performed as environmental protection in developed economies, along with some empirical evidence supporting our conclusion that we should be cautious in assessing the merits of such an environmental protection, especially whenever it mainly consists of reactive measures. Section 5 presents concluding remarks and suggests possible directions for future research.

\section{The Benchmark Model}

Our benchmark model is a Ramsey-type growth model with economic and environmental interaction. As in Gradus and Smulders (1993) we assume no productive role for the environment. Households receive rents, pay a proportional tax on income, purchase a consumption good and choose how much to save. Firms produce the consumption good with an undesired side-effect of emissions of pollutants. The government collects taxes from households and uses them (through the EPA) to finance environmental protection services 3 . The environment evolves over time according to its pollution absorption capacity but deteriorates with net (of abatement activities) emissions of pollutants. For the sake of simplicity we assume that the household size is constant and normalized to one; thus, we present the model directly in per-capita terms (and we abstract from labor).

Environmental quality, $E_{t}$, is a stock variable, whose dynamics depends on its pollution absorption capacity, $R\left(E_{t}\right)$, and unabated emissions, $X_{t}$. We assume the absorption function to be linear in environmental quality, $R\left(E_{t}\right)=\theta E_{t}$, where $\theta>0$ represents the natural rate of absorption. As in Michel and Rotillon (1995), pollution, $P_{t}$ is assumed to depend on physical production and to be proportional to final output, $P_{t}=\left(\nu Y_{t}\right)^{\phi}$, where $Y_{t}$ is output and $\nu, \phi>0$ measure the environmental efficiency of the production process. As in Gradus and Smulders (1993), some resources are allocated to reduce the impact of these emissions on the environment, and unabated emissions result to be given by $X_{t}=\left(\frac{\nu Y_{t}}{A_{t}}\right)^{\phi}$, where $A_{t}$ represents abatement activities. Thus, given its initial condition, $E_{0}$, environmental quality evolves over time according to the following differential equation:

$$
\dot{E}_{t}=R\left(E_{t}\right)-\left(\frac{\nu Y_{t}}{A_{t}}\right)^{\phi}
$$

The household's problem consists of maximizing its welfare given its initial capital endowment $K_{0}$ and the law of motion of capital, $K_{t}$, by choosing how much to consume. Welfare is the infinite discounted sum ( $\rho$ is the pure rate of time preference) of instantaneous utilities, which depend both on consumption, $C_{t}$, and environmental quality. The instantaneous utility function is assumed to take the following isoelastic form: $u\left(C_{t}, E_{t}\right)=\frac{\left(C_{t} E_{t}^{\beta}\right)^{1-\sigma}-1}{1-\sigma}$, where $\sigma>1$ is the inverse of the intertemporal elasticity of substitution and $\beta \geq 0$ represents the weight of environmental quality in household's preferences (the green preferences parameter).

\footnotetext{
${ }^{3}$ Note that this model applies for the structure of developed economies that have built up enough institutional capacity as to effectively enforce environmental protection activities.
} 
The household's problem reads as:

$$
\begin{array}{rl}
\max _{C_{t}} & W=\int_{0}^{\infty} \frac{\left(C_{t} E_{t}^{\beta}\right)^{1-\sigma}-1}{1-\sigma} e^{-\rho t} d t \\
\text { s.t. } & \dot{K}_{t}=(1-\tau) r_{t} K_{t}-C_{t},
\end{array}
$$

where $r_{t}$ is the interest rate and $\tau \in[0,1]$ the income tax rate. Following Rebelo (1991), output is produced by competitive firms (owned by the household) according to an AK technology, $Y_{t}=a K_{t}$, where $a>0$ is a technology scale parameter.

As in Huang and Cai (1994), the government levies taxes on households in order to finance environmental protection activities, maintaining a balanced budget at any point in time. Taxes are proportional to income, meaning that $G_{t}=\tau Y_{t}$, where $G_{t}$ is public spending. Public spending is completely devoted to abatement activities, and the abatement technology is linear in public spending, thus we assume $A_{t}=\mu G_{t}$, where $\mu$ represents the efficiency of abatement activities.

In general equilibrium, the markets clear and agents (households and firms) maximize their objective function (welfare and profits, respectively), taking environmental quality as given. The closed-economy resource constraint implies that output is allocated among consumption, public spending and investments in capital accumulation: $Y_{t}=C_{t}+\dot{K}_{t}+G_{t}$. The economic dynamics is totally summarized by the following three equations, describing capital accumulation, consumption growth and environmental quality dynamics:

$$
\begin{aligned}
\dot{K}_{t} & =(1-\tau) a K_{t}-C_{t} \\
\frac{\dot{C}_{t}}{C_{t}} & =\frac{1}{\sigma}\left[(1-\tau) a-\rho+\beta(1-\sigma) \frac{\dot{E}_{t}}{E_{t}}-\right] \\
\dot{E}_{t} & =\theta E_{t}-\left(\frac{\eta}{\tau}\right)^{\phi},
\end{aligned}
$$

where $\eta=\frac{\nu}{\mu}$ represents the relative efficiency of environmental services (if $\nu=\mu$, one unit of environmental service perfectly offsets the emissions generated by one unit of physical production). Through the analysis of the economic and environmental constraints, we can immediately understand the role of the (environmental) tax, namely $\tau$ reallocates resources from capital accumulation (physical investment) to environmental protection (green activities). Thus, $\tau$ is the policy instrument available to policymakers in order to implement softer or tighter environmental policy regimes, represented by lower or higher values of the tax parameter respectively. Moreover, note that the role of the government in managing the growth and environment trade-off is crucial, since agents' utility depends on both consumption and environmental quality. If the government neglects the importance of environmental quality and chooses not to allocate resources to environmental preservation $(\tau=0)$, this will imply a faster capital accumulation and thus a higher economic growth rate, but at the same time a much faster environmental degradation. In such a scenario, welfare will be dominated by environmental dynamics and will converge to zero. Such an outcome is clearly not optimal, and in order to rule this scenario out, we assume that the government wishes to ensure a minimal environmental quality level, namely $E_{t}>\widetilde{E}, \forall t$. Since this minimal environmental level is completely discretionary, without loss of generality, we assume $\widetilde{E}=0$.

By analyzing the previous equations it is clear that along a balanced growth path (BGP) equilibrium the growth rate of capital, output and consumption must coincide. In the long run the economy will show strictly positive growth if $\rho<(1-\tau) a$. As extensively shown in the one-sector endogenous growth and environment literature, such a BGP is sustainable since consumption is increasing and environmental quality does not fall below the minimal environmental level $\widetilde{E}=0$ (see Smulders, 1999; or recently, Marsiglio, 2011). Along the BGP, economic growth, $\gamma=\gamma_{C}=\gamma_{K}=\gamma_{Y}$, and environmental quality are respectively given by:

$$
\begin{aligned}
\gamma & =\frac{a(1-\tau)-\rho}{\sigma} \\
\bar{E} & =\frac{\eta^{\phi}}{\theta \tau^{\phi}} .
\end{aligned}
$$


where $\bar{E}$ represents the (constant) steady state value of environmental quality. Note that the economy does not show any transitional dynamics, since we are in an AK-type framework This means that the economy lies on its BGP equilibrium from time 0, and this, as usual in the endogenous growth literature, has to be interpreted as a representation of its long run outcome. Because of such a peculiarity of the AK setup, it is also possible to explicitly derive the welfare level, which turns out to be equal to:

$$
W=\frac{1}{\rho(\sigma-1)}-\frac{\sigma C_{0}^{1-\sigma} E_{0}^{\beta(1-\sigma)}}{(\sigma-1)[\rho+(\sigma-1)(1-\tau) a]},
$$

where $E_{0}=\bar{E}$. Note that the government, simply by reallocating resources from one sector to the other, can ensure that the economic goal (income growth) does not conflict with the environmental goal (non-zero environmental quality); see equations (7) and (8). Since our primary aim consists of understanding which role environmental policy might be play in achieving such goals, we now need to investigate further the relationship between the policy tool $\tau$ and both economic and environmental performances. Specifically, in the following we use the term 'win-win outcome', according to Porter and van der Linde's (1995) definition, to refer to any outcome in which environmental policy can be used to simultaneously promote growth and environmental improvements. The result can be stated as follows:

Proposition 1. In an economy characterized by (4), (5) and (6), along the BGP win-win outcomes exist. Softer environmental policy regimes imply both faster economic growth and better environmental quality, increasing welfare.

Proof. It is straightforward to show that along the BGP both the growth rate, $\frac{\partial \gamma}{\partial \tau}=-\frac{a}{\sigma}<0$, and environmental quality, $\frac{\partial \overline{\bar{E}}}{\partial \tau}=-\frac{\phi \eta^{\phi}}{\theta \tau^{\phi+1}}<0$, are negative functions of the tax rate. Thus, softer environmental policy regimes lead both to higher growth and environmental quality, resulting to be also welfare improving. Indeed, the welfare, is a monotonically decreasing function of $\tau$ :

$$
\frac{\partial W}{\partial \tau}=\frac{-\sigma C_{0}^{1-\sigma} \eta^{\beta \phi(1-\sigma)}\{\beta \phi(\sigma-1) \rho+(\sigma-1)[\tau+\beta \phi(\sigma-1)(1-\tau)] a\}}{(\sigma-1) \theta^{\beta(1-\sigma)}[\rho+(\sigma-1)(1-\tau) a]^{2} \tau^{1+\beta \phi(1-\sigma)}}<0 .
$$

Note that even if welfare is affected by $\tau$ through two different channels, the economic growth rate and the level of environmental quality, they both affect welfare in the same direction.

Proposition 1 shows that economic growth and environmental preservation go hand-in-hand along the BGP. Contrarily to Gradus and Smulders (1993), it is possible to use environmental policy to generate faster growth and environmental improvements at the same time. Note that this is possible even if there is no productivity effect and a unique form of capital is considered. As discussed in our introduction, some other studies also show that win-win outcomes exist, but they do so by introducing either productivity effects or further types of capital (see Smulders, 1999; and Ricci, 2007). The main difference between our result and this literature (and the original win-win opportunity, as proposed by Porter and van der Linde, 1995) lies in the fact that we cannot support its optimistic view on environmental policy. Indeed, a stricter environmental regulation may deteriorate environmental quality and reduce economic growth in the long run. Thus, in order to achieve both the environmental and economic goals, the government should implement softer environmental policy regimes, and this will also increase welfare 5 . To the best of our knowledge, the only paper presenting some result similar to ours is Fodha's (2010), which shows that, in a completely different framework with overlapping generations where environmental protection activities

\footnotetext{
${ }^{4}$ It is straightforward to show that both the benchmark model and the model analyzed in the next section do not show any transitional dynamics. Further details can be found in an appendix available from the authors upon request.

${ }^{5}$ This is due to the fact that in steady state the environmental quality results to be constant (and decreasing in $\tau$ ), and therefore in the long run welfare is driven by consumption growth. Note that if this was not the case, the result could be different, as stressed by Gradus and Smulders (1993) and Hettich (1998), among others.
} 
are partly the result of individual voluntary actions and partly the result of public intervention, under certain conditions (and thus this does not have necessarily to happen) stricter environmental public policy regimes can be harmful for the environment. Our result is stronger than Fodha's (2010) since the negative implications of strict environmental policy regimes hold true for any parameter configuration consistent with a BGP equilibrium and moreover our setup is much simpler. Indeed, our framework is extremely basic, and Proposition 1 does not require the presence of any ad-hoc assumption, as for example cleaning technological progress, suggesting thus that green growth is possible even without environmentally friendly technical progress: reallocation of resources is enough.

\section{A Different Specification}

The model previously described relies upon Gradus and Smulders' (1993) specification of unabated emissions. However, such unabated emissions go to infinity as abatement goes to zero, meaning that pollution is not a joint product of output (Brock and Taylor, 2005). In order to consider a more realistic formulation, we now slightly modify our benchmark model contrasting the results under these two different specifications. As in Economides and Philippopoulos (2008) we assume that environmental dynamics is linear in abatement activities:

$$
\dot{E}_{t}=\theta E_{t}-\left(\nu Y_{t}\right)^{\phi}+A_{t}
$$

whereas pollution is maintained as in section 2, that is $P_{t}=\left(\nu Y_{t}\right)^{\phi}$. Similarly to Bartz and Kelly (2008), unabated pollution is now assumed to be represented by $X_{t}=\nu Y_{t}^{\phi}-A_{t}=\nu\left(1-u_{t}\right) a^{\phi} K_{t}^{\phi}$, where $u_{t} \in[0,1]$ represents the share of emissions abated by purposive governmental activities. Thus, unabated emissions go to infinity only if production goes to infinity. Such a specification is more consistent with the idea that pollution is a side product of economic production ${ }^{6}$.

The government uses the tax revenue to determine which share of emissions to abate taking into account its associated cost: $\tau=c(u)$, where $c(\cdot)$ is the cost function which, as in Kelly (2003), is assumed to be increasing and convex, i.e. $c^{\prime}>0$ and $c^{\prime \prime}>0$. As in Bartz and Kelly (2008), for the sake of simplicity, we specify this function as follow: 7 : $c(u)=1-(1-u)^{\epsilon}$, where $\epsilon>1$.

In general equilibrium, the economic dynamics is represented by the following equations:

$$
\begin{aligned}
\dot{K}_{t} & =(1-u)^{\epsilon} a K_{t}-C_{t} \\
\frac{\dot{C}_{t}}{C_{t}} & =\frac{1}{\sigma}\left[(1-u)^{\epsilon} a-\rho+\beta(1-\sigma) \theta-\beta(1-\sigma) \eta(1-u) \frac{K_{t}^{\phi}}{E_{t}}\right] \\
\dot{E}_{t} & =\theta E_{t}-\eta(1-u) K_{t}^{\phi} .
\end{aligned}
$$

where $\eta=\nu a^{\phi}$. Comments similar to those discussed in the previous section apply also in this context. However, in this framework, along the BGP equilibrium, environmental quality is no longer constant but it grows at a rate proportional to the growth rate of capital; see equation (13). In particular, provided that $\rho<(1-u)^{\epsilon} a$, the economic (and environmental) growth rate, $\gamma=\gamma_{C}=\gamma_{K}=\gamma_{Y}=\frac{\gamma_{E}}{\phi}$, and the welfare

\footnotetext{
${ }^{6}$ An even simpler formulation of unabated emissions consistent with the fact that pollution is a by-product of production activities and at the same time more closely related to Gradus and Smulders' (1993) is $X_{t}=\left(\frac{\nu Y_{t}}{1+A_{t}}\right)^{\phi}$. In such a case it is straightforward to show that in our setup along the BGP the economic growth rate and level of environmental quality are exactly as in (7) and (8), thus the results in Proposition 1 1 still hold. It seems therefore convenient to focus on an alternative specification which gives rise to different but comparable results with those in our baseline model.

${ }^{7}$ It is possible to show that our results hold for any increasing and convex cost function. Thus, it seems convenient to present our results in the simplest possible form, following the specification used by Bartz and Kelly (2008). See also Marsiglio (2015) for a discussion of a similar model applied to tourism destinations.
} 
level are respectively given by the following expressions:

$$
\begin{aligned}
\gamma & =\frac{\gamma_{E}}{\phi}=\frac{a(1-u)^{\epsilon}-\rho}{\sigma+\beta \phi(\sigma-1)} \\
W & =\frac{1}{\rho(\sigma-1)}-\frac{\sigma C_{0}^{1-\sigma} E_{0}^{\beta(1-\sigma)}[\sigma+\beta \phi(\sigma-1)]}{(\sigma-1)\left[\rho+(\sigma-1)(1+\beta \phi)(1-u)^{\epsilon} a\right]} .
\end{aligned}
$$

From equation (14), it is clear that along the sustainable BGP economic and environmental performances move in the same direction, thus any policy fostering economic growth will also improve environmental quality (thus welfare since there is no transitional dynamics). Specifically, also in this case a softer environmental policy, represented by $u$ (or equivalently by $\tau$ since the relationship between $\tau$ and $u$ is monotonically increasing), will lead to a win-win outcome.

Proposition 2. Also in an economy characterized by (11), (12) and (13), along the BGP softer environmental policy regimes are win-win: they lead to faster economic growth and better environmental quality, thus increasing welfare.

Proof. The result is straightforward since from 14 and 15 , we have $\frac{\partial \gamma}{\partial u}=-\frac{\epsilon(1-u)^{\epsilon-1} a}{\sigma+\beta \phi(\sigma-1)}<0$, and $\frac{\partial W}{\partial u}=$ $-\frac{\sigma \epsilon C_{0}^{1-\sigma} E_{0}^{\beta(1-\sigma)}[\sigma+\beta \phi(\sigma-1)](\sigma-1)(1+\beta \phi)(1-u)^{\epsilon-1} a}{(\sigma-1)\left[\rho+(\sigma-1)(1+\beta \phi)(1-u)^{\epsilon} a\right]}<0$.

Proposition 2 clearly shows that also under a different model formulation, the same results derived in our benchmark model still apply. This suggests that our (pessimistic) conclusion about the relationship between environmental policy and both economic and environmental performances are not strictly dependent upon the functional forms adopted to describe unabated emissions. Both Gradus and Smulders' (1993) and Bartz and Kelly's (2008) formulations lead to the same qualitative results: win-win outcomes exist but, differently from what shown in the previous literature, they may be achieved through softer environmental policy regimes.

\section{Discussion}

We have analyzed two very simple models of endogenous growth with environmental degradation due to production activity. They show that the government, by levying taxes on consumers (which in our framework are completely equivalent to taxes on firms' revenue) and allocating the tax revenue to environmental protection activities can ensure that the economy will reach a sustainable BGP. Moreover, along the BGP win-win outcomes in which economic and environmental performance go hand-in-hand can be found even if environmental quality does not play any productive role. However, softer environmental policy regimes (represented by lower tax rates in our benchmark model, or lower shares of abated emissions in our second specification) may be needed to promote fast economic growth and environmental improvements. Our results need to be taken with a pinch of salt, since the models are extremely stylized and some of the simplifying assumptions, in particular those related to the nature of environmental protection activities, need to be carefully interpreted.

In order to understand the implications of modelling environmental protection activities as specified in equations (1) and (10), let us first revise some concepts regarding these activities. The United Nations System of Environmental-Economic Accounts (SEEA) in its white cover version of the SEEA Central Framework published in May 2012 (UNSD, 2012) explains the compilation of two sets of information for the analysis of environmental transactions, namely the Environmental Protection Expenditure Account (EPEA) and the statistics on the Environmental Goods and Services 8 Sector (EGSS). Both the EPEA and the EGSS provide

\footnotetext{
${ }^{8}$ Environmental goods and services are different from ecosystem services which is the term used to describe various flows (e.g. extracted natural resources, pollination by bees, soil formation) within the environment and from the environment to the economy and society. In contrast, environmental goods and services in the SEEA comprise only flows of products within the economy.
} 
information that assist in understanding society's response to the challenge of environmental degradation, and the potential for economic activity to be based on environmentally friendly activities. EPEA takes a "demand" perspective and would reflect in our framework the resources devoted to abatement activity $(G=\tau Y)$. Instead, statistics on the EGSS take a "supply" perspective and in our context it would provide information on the type of services provided to clean up the environment $(A)$. The environmental goods and services in scope of the EGSS are classified into four categories: (i) environmental specific services (e.g. waste-water management services), (ii) environmental sole-purpose products (e.g. catalytic converters), (iii) adapted goods (e.g. mercury-free batteries), and (iv) environmental technologies, which in turn could be sub-classified into end-of-pipe (pollution treatment) technologies and integrated (pollution prevention) technologies. This description gives us an idea of the wide range of activities that could potentially be labeled as environmental protection activities. Therefore, it should come as no surprise to realize that equations (1) and $(10)$, in their simplicity, are not able to capture all such activities.

But, then, which are the environmental protection activities that are represented in equations (1) and (10)? Two important features of such activities are the following: $(i)$ these activities are just meant to mitigate anthropogenic emissions and (ii) these activities are "flows" (current expenditures), as opposed to "stocks" (investments) that do accumulate over time. This means that we are representing the use of energy, material, maintenance and personnel for producing environmental services such as waste management, wastewater treatment, or reducing and treating air emissions, due to the fact that the scale of economic activity has exceeded the natural regeneration capacity of Nature (its capacity to provide ecosystem services). The expenditures we are considering do not represent changes in consumption patterns, nor in production technologies. Therefore, the relevant question is whether our specification of the model is representative of the current situation regarding environmental protection expenditure undertaken in developed countries. Probably, the quality of the information regarding environmental protection expenditure currently available does not allow us to give a clear answer. Information regarding environmental protection expenditure is very limited for several developed countries. The European Union (EU) is probably one of the regions in the world for which most detailed information is available regarding environmental protection expenditure. Thus, according to Eurostat (2015), EU-28 environmental protection expenditure accounted for $2.20 \%$ of GDP in 2013, 70-80\% of environmental protection expenditure was current expenditure and this expenditure was distributed approximately $48 \%$ to waste management, $25 \%$ to waste-water treatment, another $8 \%$ to reducing and treating air emissions and the rest to other measures such as protection of soil and groundwater, biodiversity protection, noise reduction, protection against radiation and environmental research and development. We can also list many examples of environmental protection expenditures that fit in our model, that is, they comprise mainly current expenditure and have been undertaken due to a loss of Nature's capacity to provide certain ecosystem services. Some examples include expenditures associated with the provision of drinking water for regions where ground-water reserves have not been properly managed due to activities such as excessive irrigation or pesticide and fertilizer application ${ }^{9}$, expenditures related to restoration and clean-up of a river-basin due to poorly managed land-uses upstream 10 , expenditures related to air conditioning in urban areas where the replacement of the vegetated land surface with impervious and dark surfaces of buildings have created a urban heat island effect 11 , etc.

Our results should suggest caution in judging the merits of expenditure in environmental protection activities. Simply stating that allocating larger shares of GDP to protect the environment is not enough to effectively achieve higher environmental standards. Indeed, even if current expenditure in providing

\footnotetext{
${ }^{9}$ The Fourth Report to Congress on Drinking Water Infrastructure Needs and Survey Assessment (US EPA, 2009) estimates that in the US 334.8 billion dollars are needed in infrastructure investments over the next two decades to ensure safe drinking to its population.

${ }^{10} \mathrm{Fu}$ et al. (2012) estimate that the water quality restoration costs in Yonding River Basin (China) is 260 million yuan.

${ }^{11}$ Akbari (2005) estimates that the cooling energy savings in US from cool surfaces and shade trees, when fully implemented, is about $\$ 5$ billion per year.
} 
environmental services to replace certain ecosystem services may be considered an economic stimulus 5 to both production and employment as well as a relief to maintain certain level of environmental quality in the short term (see Jaeger et al., 2011), in the long run it could even imply a burden that hampers economic growth and condemns our society to live with a less healthy environment.

\begin{tabular}{|c||c|c|c|c|c|c|c|}
\hline COUNTRY & ID & EPE & EPE_INV & EPE_CUR & ENV & DENV & GROWTH \\
\hline \hline Austria & AT & 0.44 & 0.09 & 0.35 & 3.2 & $-18 \%$ & 1.4 \\
\hline Belgium & BE & 0.63 & 0.07 & 0.56 & 1.1 & $0 \%$ & 1.3 \\
\hline Bulgaria & BG & 1.06 & 0.48 & 0.58 & 2.9 & $21 \%$ & 3.7 \\
\hline Croatia & HR & 0.32 & 0.31 & 0.01 & 2.7 & $8 \%$ & 1.9 \\
\hline Cyprus & CY & 0.51 & 0.13 & 0.38 & 0.4 & $-43 \%$ & 0.6 \\
\hline Czech Republic & CZ & 0.48 & 0.24 & 0.24 & 2.6 & $0 \%$ & 2.2 \\
\hline Denmark & DK & 0.64 & 0.07 & 0.57 & 4.5 & $0 \%$ & 0.8 \\
\hline Estonia & EE & 0.31 & 0.24 & 0.07 & 9.9 & $16 \%$ & 5.0 \\
\hline Finland & FI & 0.64 & 0.09 & 0.55 & 13.2 & $-9 \%$ & 2.0 \\
\hline France & FR & 0.59 & 0.12 & 0.47 & 2.9 & $-24 \%$ & 1.0 \\
\hline Germany & DE & 0.33 & 0.08 & 0.25 & 2.1 & $17 \%$ & 1.3 \\
\hline Greece & GR & 0.73 & 0.20 & 0.53 & 1.5 & $0 \%$ & 0.7 \\
\hline Hungary & HU & 0.42 & 0.32 & 0.10 & 2.4 & $26 \%$ & 2.4 \\
\hline Ireland & IE & 0.77 & 0.26 & 0.51 & 3.8 & $-25 \%$ & 2.4 \\
\hline Italy & IT & 0.88 & 0.19 & 0.69 & 1.1 & $0 \%$ & 0.1 \\
\hline Latvia & LV & 0.73 & 0.15 & 0.58 & 8.8 & $32 \%$ & 5.6 \\
\hline Lithuania & LT & 0.56 & 0.15 & 0.41 & 4.2 & $14 \%$ & 5.7 \\
\hline The Netherlands & NL & 1.44 & 0.29 & 1.15 & 1.1 & $-8 \%$ & 1.4 \\
\hline Norway & NO & 0.79 & 0.26 & 0.53 & 8.4 & $-9 \%$ & 1.4 \\
\hline Poland & PL & 0.48 & 0.27 & 0.21 & 2 & $5 \%$ & 4.0 \\
\hline Portugal & PT & 0.44 & 0.07 & 0.37 & 1.5 & $7 \%$ & 1.0 \\
\hline Romania & RO & 0.46 & 0.10 & 0.36 & 2.6 & $4 \%$ & 3.3 \\
\hline Serbia & RS & 0.07 & 0.00 & 0.07 & 1 & $50 \%$ & 3.2 \\
\hline Slovakia & SK & 0.28 & 0.06 & 0.22 & 2.8 & $-3 \%$ & 3.6 \\
\hline Slovenia & SI & 0.70 & 0.40 & 0.30 & 2.3 & $0 \%$ & 2.4 \\
\hline Spain & ES & 0.22 & 0.06 & 0.16 & 1.5 & $0 \%$ & 1.2 \\
\hline Sweden & SE & 0.33 & 0.03 & 0.30 & 10.5 & $-16 \%$ & 2.0 \\
\hline Switzerland & CH & 0.83 & 0.27 & 0.56 & 1.4 & $-44 \%$ & 1.2 \\
\hline United Kingdom & GB & 0.91 & 0.15 & 0.76 & 1.4 & $27 \%$ & 1.6 \\
\hline & & & & & & & \\
\hline
\end{tabular}

Table 1: Growth, biocapacity and public environmental protection expenditure in European countries. [Source: Eurostat (2015) and GFN (2015)]

Table 1 presents some empirical evidence that backs up our conclusion that we should be cautious in assessing the merits of environmental protection expenditure. The table contains information for 29 countries in Europe on (i) total public environmental spending (as a percentage of GDP) in 2013 [EPE], its decomposition into (ii) investment [EPE_INV] and (iii) current expenditure [EPE_CUR], (iv) state of the

\footnotetext{
${ }^{12}$ One of the many criticisms to the System of National Accounts is that "defensive expenditures made to eliminate, mitigate, neutralize, or anticipate and avoid damages and deterioration that industrial society's process of growth has caused to living, working, and environmental conditions' (Leipert, 1989) should be eliminated from measures of aggregate final output such as the National Net Product. Thus, many economists have defended that environmental defensive expenditure should be treated as depreciation of (natural) capital and therefore should not be computed as "Hicksian" income (Weitzman, 2003).
} 
environment (proxied by the number of hectares of productive land and water per person) [ENV], (v) the rate of change of the state of the environment from 1961 to 2011 [DENV] and (vi) the annual average rate of growth GDP per capita from 1995 to 2014 [GROWTH]. Data on environmental spending and GDP per capita growth rates come from Eurostat (2015). Data on biocapacity (hectares of productive land and water per person) come from GFN (2015). In order to identify different types of countries based on the linkages between sustained growth rates, status of the environment and public effort on environmental preservation we apply an agglomerative hierarchical clustering algorithm (Jain and Dubes, 1988). The results are illustrated with the help of a dendogram 13 in Figure 1. Cutting the dendogram at some intermediate height, we can partition the sample of countries into 2, 4 or 6 clusters. The higher the height of the cut, the more heterogeneous the resulting clusters will be. In Table 2 we compare mean values of environmental protection expenditure, environmental quality and growth rates for the first two clusters from the left (the two most numerous clusters) of the 6-clusters partition (the other four clusters include less than two countries each).

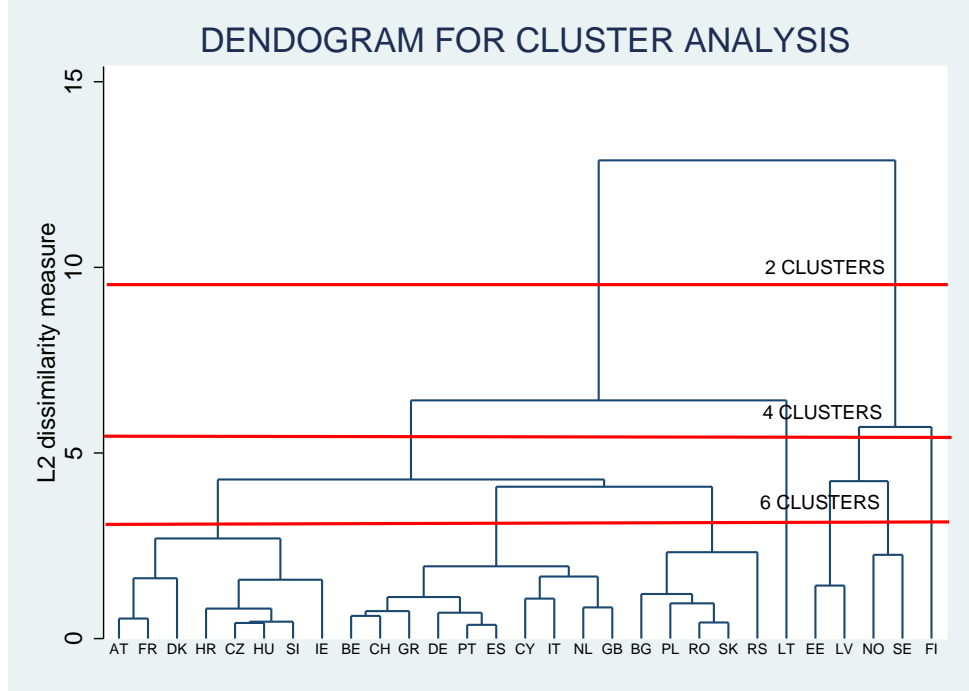

Figure 1: Dendogram for cluster analysis. [Source: Our own calculations.]

Note that according to Table 2, the first cluster (AT, HR, CZ, DK, FR, HU, IE, SI) enjoys on average higher growth and environmental quality and devotes lower resources to environmental protection expenditure than the second cluster (BE, BG, CY, DE, GR, IT, NL, PL, PT, RO, RS, SK, ES, CH, GB). Moreover, environmental protection in the first cluster comprises more investment activities and less current expenditure than the second cluster. This empirical results are in line with our argument above, where we pointed out that some countries may be forced to provide environmental services to replace ecosystem services and this in the long run may affect growth and the ability to maintain higher environmental quality standards. Despite such a kind of analysis cannot be considered exhaustive in analyzing the long run impact of environmental protection on economic and environmental performance, we believe it allows us to show that our model's results are not only a theoretical possibility but are supported by the experiences of some real world economies.

\footnotetext{
${ }^{13} \mathrm{~A}$ dendrogram is a hierarchical tree structure formed by links that join couples of clusters together in a new cluster from the beginning (singleton clusters i.e., one cluster per country) to the end (a unique cluster including the whole set of countries) of the tree. The heights of the links correspond to the distance between the couple of clusters joined as a new cluster under the link. The similarity measure between clusters depends on the linkage function defined in the algorithm. In this particular exercise we use the Complete Link (furthest neighbor) as the linkage function.
} 


\begin{tabular}{|c|c||c|c|}
\hline FIRST CLUSTER & MEAN & SECOND CLUSTER & MEAN \\
\hline \hline EPE & 0.55 & EPE & 0.62 \\
\hline EPE_INV & 0.23 & EPE_INV & 0.16 \\
\hline EPE_CUR & 0.32 & EPE_CUR & 0.46 \\
\hline ENV & 3.05 & ENV & 1.6 \\
\hline DENV & $-4 \%$ & DENV & $2 \%$ \\
\hline GROWTH & 2.4 & GROWTH & 1.9 \\
\hline
\end{tabular}

Table 2: Comparison of mean values for the first and the second clusters

\section{Conclusion}

The crisis we have faced over the last few years has convinced policymakers from several countries that a different kind of economic growth is needed. Thus, many governments have devised "green recovery plans" as a way of reviving demand, creating jobs and accelerating the transition to a more sustainable economy. However, there is considerable diversity in the plans that have been issued to date. Some measures lack the long term perspective that corresponds to green policies and focus more on recovery from the crisis rather than changing production and consumption patterns. Going green can be a long term driver for economic growth and environmental quality preservation, through, for example, investing in renewable energy and improving the efficiency in energy and materials use. However, it can also imply a "reactive" short term response to environmental degradation through measures that simply substitute for services that a healthier environment would otherwise provide. As noted before, EU-28 environmental protection expenditure accounted for $2.20 \%$ of GDP in 2013 and $70-80 \%$ of environmental protection was current expenditure devoted to activities such as water and air quality regulation and waste management (Eurostat,2015).

In this paper we use two very simple endogenous growth models with environmental degradation to illustrate that in the long run a lower level of environmental protection expenditure may be beneficial both for economic growth and, more surprisingly, for the environment. This is due to the fact that environmental protection activities captured by the model are not "proactive" measures that look for technological and structural changes, thus facilitating de-linking economic growth from environmental degradation in the long run, but they only contemplate the use of energy, material, maintenance and personnel to compensate Nature's reduced capacity to provide essential ecosystem services, such as air quality and climate regulation, water purification and waste treatment. The main conclusion that can be drawn from our analysis is that a high level of environmental protection expenditure is neither a necessary nor a sufficient condition for a greener future. If we focus on replacing ecosystem services provided by Nature with current environmental expenditure and do not provide incentives to the development of new technologies, which can contribute to improve environmental performance and achieve green growth targets (by replacing resource-intensive and polluting activities or improving the environmental and economic efficiency of existing ones), we will be condemned to live in a world with poor environmental quality and a very expensive environmental maintenance bill.

Since the types of environmental protection activities that we could describe in our models are only reactive measures, for future research it might be interesting to extend our analysis in order to allow also for proactive measures to be taken into account. In such a framework, provided that some proactive environmental protection activity is undertaken the results might be substantially different. Thus, it might be interesting to understand to what extent proactive measures can compensate for the (long run) negative impacts generated by tighter (reactive) environmental policy regimes on both economic growth and environmental performance. Moreover, our model does not take into account other issues which have been often discussed in the growth and environment literature, including irreversibilities (Pommeret and Prieur, 2013) 
and unbalanced budgets (Fodha and Seegmuller, 2014); understanding to what extent such factors might alter our conclusions about the desirability of environmental protection might shed some further light on the role of economic and environmental policy. Extending the analysis along these directions if left for future research.

\section{References}

1. Akbari, H. (2005). Energy saving potentials and air quality benefits benefits of urban heat island mitigation, Report of the Heat Island Group, Lawrence Berkeley National Laboratory, available online at http://www.osti.gov/bridge/servlets/purl/860475-UlHWIq/860475.PDF

2. Brock, W.A., Taylor, M.S. (2005). Economic growth and the environment: a Review of theory and empirics, in (Aghion P., Durlauf, S., Eds.) "Handbook of Economic Growth", vol.1 (Elsevier:Amsterdam, Netherlands)

3. Bartz, S., Kelly, D.L. (2008). Economic growth and the environment: theory and facts, Resource and Energy Economics 30, 115-149

4. Chevé, M. (2000). Irreversibility of pollution accumulation, Environmental and Resource Economics $16,93-104$

5. Economides, G., Philippopoulos, A. (2008). Growth enhancing policy is the means to sustain the environment, Review of Economic Dynamics 11, 207-219

6. Eurostat (2015). Environmental protection expenditure in Europe - Data 2003-2013, available online at: http://ec.europa.eu/eurostat/statistics-explained/... ...index.php/Environmental_protection_expenditure\#Further_Eurostat_information

7. Fodha, M. (2010). Could environmental public policy be harmful for the environment?, Recherches Economiques de Louvain - Louvain Economic Review 76, 371-390

8. Fodha, M., Seegmuller, T. (2014). Environmental quality, public debt and economic development, Environmental and Resource Economics 57, 487-504

9. Fu, Yi-Cheng, Ben-Qing Ruan, Chun-Ling Zhang, Xu, Feng-Ran (2012), Yongding river basin water environmental restoration cost, Journal of Food, Agriculture \& Environment 10, 876-883

10. GFN (2015). Footprint for Nations. Global Footprint Network. Available on-line at: http://www.footprintnetwork.org/en/index.php/GFN/page/footprint_for_nations

11. Gradus, R., Smulders, S. (1993). The trade-off between environmental care and long-term growth: pollution in three prototype growth models, Journal of Economics 58, 25-51

12. Grossman, G.M., Krueger, A.B. (1995). Economic growth and the environment, Quarterly Journal of Economics 110, 353-377

13. Hettich, F. (1998). Growth effects of a revenue-neutral environmental tax reform, Journal of Economics $67,287-316$

14. Huang, C.H., Cai, D. (1994). Constant-returns endogenous growth with pollution control, Environmental and Resource Economics 4, 383-400

15. IILS (2011). Green stimulus measures, EC-IILS Joint Discussion Paper Series N 15, Geneva: International Labor Office (ILO)

16. Jaeger, C.C., Paroussos, L., Mangalagiu, D., Kupers, R., Mandel, A., Tbara, J.D., Meiner, F., Lass, W. (2011). A new growth path for Europe. Generating prosperity and jobs in the low-carbon economy (Potsdam, PIK)

17. Jaffe, A.B., Newell, R.G., Stavins, R.N. (2003), Technological change and the environment, in (Mäler, K.G., Vincent, J.R. Eds.), "Handbook of Environmental Economics", vol. 1, ch. 11, 461-516 (NorthHolland, Amsterdam) 
18. Jain, A. K.,Dubes, R.C. (1988). Algorithms for clustering data (Prentice Hall, New Jersey)

19. Kelly, D.L. (2003). On environmental Kuznets curves arising from stock externalities, Journal of Economic Dynamics \& Control 27, 1367-1390

20. Leipert, C. (1989). Social costs of the economic process and national accounts: the example of defensive expenditures, Journal of Interdisciplinary Economics 3, 27-46

21. Markandya, A. (2005). Environmental implications of non-environmental policies, in (Mäler, K.G., Vincent, J., Eds.), "Handbook of Environmental Economics", vol. 3., ch. 26, 1353-1401 (Elsevier: Amsterdam, Netherlands)

22. Marsiglio, S. (2011). On the relationship between population change and sustainable development, Research in Economics 65, 353-364

23. Marsiglio, S. (2015). Economic growth and environment: tourism as a trigger for green growth, Tourism Economics 21, 183-204

24. Michel, P., Rotillon, G. (1995). Disutility of pollution and endogenous growth, Environmental and Resource Economics 6, 279-300

25. OECD (2015). Towards green growth: tracking progress (OECD, Paris)

26. Palmer, K., Oates, W.E., Portney, P.R. (1995). Tightening environmental standards: the benefit-cost or the no-cost paradigm? Journal of Economic Perspectives 9, 119-132

27. Pasurka, C.(2008). Perspectives on pollution abatement and competitiveness: theory, data, and analyses, Review of Environmental Economics and Policy 2, 194-218

28. Pearce, D. (1991). The role of carbon taxes in adjusting to global warming, Economic Journal 101, 938-948

29. Pommeret, A., Prieur, F. (2013). Double irreversibility and environmental policy timing, Journal of Public Economic Theory 15, 273-291

30. Porter, M.E., van der Linde, C. (1995). Toward a new conception of the environment-competitiveness relationship, Journal of Economic Perspectives 9, 97-118

31. Ramsey, F. (1928). A mathematical theory of saving, Economic Journal 38, 543-559

32. Rebelo, S.T. (1991). Long-run policy analysis and long-run growth, Journal of Political Economy 99, $500-521$

33. Ricci, F. (2007). Channels of transmission of environmental policy to economic growth: a survey of the theory, Ecological Economics 60, 688-699

34. Rosendahl, K.E. (1997). Does improved environmental policy enhance economic growth? Environmental and Resource Economics 9, 341-364

35. Shieh, J.Y., Lai, C.C., Chen, J.H. (2001). A comment on Huang and Cai's constant-returns endogenous growth with pollution control, Environmental and Resource Economics 20, 165-172

36. Smulders, S. (1995). Environmental policy and sustainable economic growth, De Economist 143, 163-195

37. Smulders, S., Gradus, R. (1996). Pollution abatement and long-term growth, European Journal of Political Economy 12, 505-532

38. Smulders, S. (1999). Endogenous growth theory and the environment, in (van den Bergh, J., Ed.), "The Handbook of Environmental and Resource Economics" (Edward Elgar: Cheltenham)

39. UN (2015). Transforming our world: the 2030 agenda for sustainable development, available on-line at: https://sustainabledevelopment.un.org/post2015/transformingourworld/publication

40. UNEP (2012). The future we want - Rio+20 outcome document, available on-line at: http://www.uncsd2012.org/thefuturewewant.html 
41. US EPA (2009). Fourth report to congress on drinking water infrastructure needs and survey assessment, US Environmental Protection Agency, Washington DC, available on-line at: http://water.epa.gov/infrastructure/drinkingwater/dwns/upload/... ...2009_03_26_needssurvey_2007_report_needssurvey_2007.pdf

42. Xepapadeas, A. (1997). Economic development and environmental pollution: traps and growth, Structural Change and Economic Dynamics 8, 327-350

43. Xepapadeas, A. (2005). Economic growth and the environment, in (Mäler, K.G., Vincent, J., Eds.), "Handbook of Environmental Economics", vol. 3., ch. 23, 1219-1271 (Elsevier: Amsterdam, Netherlands)

44. Weitzman M. (2003). Income, wealth, and the maximum principle (Harvard University Press)

45. Withagen, C. (1995). Pollution, abatement and balanced growth, Environmental and Resource Economics $5,1-8$ 